\title{
International Similarities and Differences in the Experiences and Preparation of Post-Graduate Mathematics Students as Tertiary Instructors
}

\author{
Jessica Deshler and Jessica Ellis
}

In the United States, post-graduate students are used in the teaching of undergraduate mathematics in a variety of ways, from grading papers for experienced instructors to having full responsibility of their own class. There is an established network of scholars in the US whose members examine various aspects of how these instructors are utilized, how they develop as tertiary mathematics instructors and how they are professionally prepared. There are also nationally funded initiatives underway aimed at creating stronger networks among those that wish to provide professional preparation to these instructors, those that create resources for use in professional development, and scholars that conduct research in this area.

The goal of this workshop was to bring together scholars from mathematics, education and academic development from around the world to discuss how post-graduates are (1) involved in the instruction of undergraduate mathematics and (2) how they are prepared for their teaching roles. The organizers presented an overview of what is known about both of the topic questions based on data from a large national survey conducted as a joint effort of teams from two projects whose goals are to understand and support post-graduate mathematics student instructional development in the US.

There were eleven attendees from eight countries representing post-graduate students through administrators. Participants were asked to describe the following during the workshop:

- How post-graduate students are involved in the teaching of tertiary mathematics at their institution (and how typical this is of other institutions in their country, to the best of their knowledge).

\footnotetext{
J. Deshler $(\square)$

West Virginia University, Morgantown, WV, USA

e-mail: deshler@math.wvu.edu

(C) The Author(s) 2017

G. Kaiser (ed.), Proceedings of the 13th International Congress on Mathematical

Education, ICME-13 Monographs, DOI 10.1007/978-3-319-62597-3_120
} 
- How post-graduate students are prepared for teaching tertiary mathematics at their institution (and how typical this is of other institutions in their country, to the best of their knowledge).

Workshop organizers collected written responses to these questions as the first step towards developing a written overview of the differences and similarities between nations in the practices surrounding post-graduate student instruction of tertiary mathematics. We plan to submit this overview for publication so that it can serve as the beginning of international conversations regarding the tertiary teaching preparation of post-graduate students, as well as other novice instructors (such as post-docs). Participants expressed interest in contributing to the development of an in-depth international understanding of practices related to the issues of the workshop through more formal and systematic data collection. Organizers plan to modify the US survey used to collect information on post-graduate involvement in and preparation for teaching based on the workshop discussion and comments from participants to make it applicable to the contexts of other nations. Through this ongoing work, we hope to provide international perspectives on these issues, to facilitate communication and collaboration between scholars working in similar fields in different contexts, and to identify issues for future research collaborations related to these issues.

Open Access Except where otherwise noted, this chapter is licensed under a Creative Commons Attribution 4.0 International License. To view a copy of this license, visit http://creativecommons. org/licenses/by/4.0/.

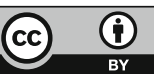

